\title{
Compatibility, sustainability, modifiability: the impact of sustainable energies in historic sites - some thoughts
}

\author{
M. Vitiello \\ Architectural History, Drawing and Restoration Department, \\ Faculty of Architecture, "Sapienza" University, Rome, Italy
}

\begin{abstract}
Following the recent introduction of an express provision in the Italian legislation regarding the adaptation of existing buildings with energy requirements, it becomes necessary to consider the applicability of the new devices related to renewable energy sources of the historical buildings and more generally the dynamics of modifiability of the existing. This is discovered through a guided reading that part of the territory and reach the cell construction and is expressed in the dialectic mutation and conservation, tradition and innovation. By defining the index of modifiability is achieved an objective parameter for assessment of the restoration project, although this will always be connected to logic evaluation, taking into account the sensitivity of the individual.
\end{abstract}

Keywords: modifiability, compatibility, adaptability, conservation, restoration, historic buildings, energy performance.

\section{Introduction}

Up to now contemporary research on the development of renewable energies has focused mainly on aspects connected with energy demand, its forms of production and distribution, as well as on the necessary materials, and their availability. These are essential components for the analysis of the ranges of applicability to the many scenarios for the utilisation of innovative technologies; however, they are prodromal to the transfer on the manufacture, which needs to be carefully assessed so that any changes imposed by the energy saving 
requirements, which are indeed a structural part of the environmental system, do not grossly change the configuration of the historical entity. In fact, although for "buildings and monuments officially protected, as designated heritage, or in view of their own architectural or historic value..." as indicated by Directive 2002/91/CE it is possible to order the exclusion from the prompt application of the relevant performance requirements, the same cannot be said for pre-industrial constructions, which are rarely under direct protection, even if they constitute the connective framework that brings together and gives life to architectural emergencies, for which, on the other, hand full conservation is demanded.

The common attitude, during the systemic and operating approach, in handling the problems connected with energy requalification for pre-existing constructions, seems to be to consider the thermal exchange between the building and the outside environment as a separate issue, both in relation to the complexity of the building, and in the consideration that the architectural manufacture may constitute an individual entity, so that it may be separated from its surroundings. Therefore, by implementing a process of extreme simplification during the procedures, the regulation calls for the assessment of the construction systems solely in terms of energy balance, or the exchange of heat between the inside and the outside of a building.

The fact that a building may not be considered only by itself, neither in terms of history nor in terms of design, but rather as part of an articulated system of connections that mankind has been able to establish between his artefacts and the territory in its orographic and environmental definition, of which they are part, seems to be the required starting point.

This is even more so when experimenting a method for reading the building framework that qualifies our historic centres, within the framework of the dialectics between continuity and mutation, between innovation and tradition, so that the conservation requirements may be matched with those for sustainability of the whole process for the modification of the existent.

The philosophy that has influenced the "studies on the city", and later on contributed to define, starting from the fifties, the sector of the restoration and recovery of historical centres, indeed considers basic building in a process and phenomenological sense, as a corpus of organic systems within space, where building, city and territory constitute living organic entities that may be compared to physical and biological metaphors. And this is what was attempted in terms of the research, of which here we wish to present the initial results, by retracing, although in summary, the steps, both in terms of the selected methods, as well as for the more general selection in terms of theoretical approach implemented for the problems arising from the modifiability of ancient constructions. The objective set was to test and define a rational path capable of recognising the factors interacting in the genesis of the historic building sector internal design process, and assess their importance, so that the inevitable transformation of the environment urbanised by human intervention for the purpose of the containment of energy consumptions may be careful and measured, and therefore in line with the idea of reducing such intervention to the minimum. The work has been aimed at the acquisition of certain intermediate 
goals, which directed towards: the reconstruction of the scalarity of the territory - settlement - building system. We have therefore tried to recreate the morphological, construction, and linguistic (meant as codification of rules and building forms) structure of the complex organic-relational system given by the building itself and by it being part of a wider context. Once collected, these data have been included in a wider analytical process where the planning quality of the restoration was considered as a unitary phenomenon of accumulation of different sets of knowledge and instrumentalities.

At the same time, it proved rather complicated to define the same "modifiability" term with reference to historical buildings; this was mostly because tare was a need for this to be connected to certain fundamental criteria of architectural restoration that are universally accepted and can be summarised in: reversibility of actions, adaptability of innovations, performance reliability of the new introductions in organically defined historical systems.

\section{The research method: from system scalarity to identification of the modifiable parameters}

The studies on urban settlements have demonstrated that these originate in ways that cannot be separated from the locations themselves, and, on the contrary, are the precise result of the relationships among the basic systems that constitute the structural mosaic of an environment. The orographic and geographical conditions, the climatic conditions, the vegetation framework and the infrastructure network, affect the creation and the development of a city, give it its own structure, a particular shape, and the specific relations that are created with the environment. Christian Norberg-Schulz points out that "ancient populations took their environment as consisting of defined features. In particular, they recognised the absolute importance of finding an agreement with the genus of the location where they were to exist" [1]. This statement entails the identification of two fundamental concepts: first of all that a settlement has an unlimited range of relations with the history of the territory in which it exists (a history made by the individuals and the communities existing in it), but this is not all, because there is also the inborn admission that in the past the survival of mankind originated from the good relation that he and its products were capable to establish with a location. And this brings back to a very actual debate such as the one developed both by bioclimatic architecture, which deals with the relation between new building and context, and by urban restoration, which deals with the conservation of the connection between the anthropic context and the environment, this superior unit that brings together town planning, landscapes, and also cultural heritage. In view of these considerations, it is possible to relate the idea of habitat developed in ecology with the idea of space continuity encompassing the territory, the settlement, and the building. In fact the habitat may also be interpreted as the group of the environmental conditions and the artificial structures created by mankind for the appropriation of a space; and in the reciprocity of this relationship it will be possible to identify the overall existing heritage with the environmental context of which it is the product. In 
defining the survey, the objective was to transcribe such observations in a conceptual and operating matrix, brought together in a methodological process for the understanding and the identification of the system elements on which one can act in terms of a possible modification of the existent. The cognitive matrix was imposed in a way to attribute to a "general introductory section" the main element for the explanation of the connection between the settlement and its site, uniting the building to the wide scale of the territory, with its wider construction processes, and just as rich strategies, to ensure correlation among the various players of the transformation. The analysis of the location is carried out using the main components of the structural mosaic, consisting of individual artificial and natural elements, dynamic and static units, which interpolation offers the possibility of detecting the general reciprocal influence issues, as well as identifying the specific objectives, which can only find their solution in a continuous feedback process, or in the assessment of the different scales.

The in depth study on the geomorphological, botanical and vegetation properties of a territory is part of this type of interpretation, where the climate characteristics do not only indicate the temperature differences between winter and summer for a certain location, but also represent an important description of the same. Climate is in fact a totalising phenomenon: it "is the sum of the atmospheric situations occurred in a certain location over the year, or the years" [2] something which, in other words, has an impact on living things and therefore on people and its activities, including architecture, which is the tool used by mankind to manage his relationship with the environment and defend himself from the aggression from atmospheric occurrences, through solutions that are indicative of the so-called "vernacular" structures.

In this way, the need for collecting the maps of the environmental statistical data and the themes relating to local habitats and ecosystems, in addition to the investigation of scientific literature for the detection of the ecologic status of sensitive environments, is not a redundant requirement. It is, on the other hand, part of the complexity of the analysis, which must be intended both as a cognitive and an interpretative operation, in other words not unrelated to the project process, the ultimate objective of which is the understanding of the transformation potentials of the settlement system, on the basis of the ecosustainable objectives set as concept references [3].

In the same way, a decision was made to also include in the site investigation procedure the computer simulations relating to exposure to the sun and the seasonal trend of ventilation. This type of study was based on territory digital and three-dimensional models, which gives the possibility of identifying the bioclimatic criticalities, to provide data for the active and passive exploitation of solar energy, and the use of ventilation for passive summer cooling. Together with these elements, the global assessment of the building-environment system also includes the simulation of the risks relating to the flow of meteoritic waters, and their recovery inside collection basins. While the qualification and quantification of the vegetation of the site gives the possibility of identifying the ecological dynamics of the landscapes and gives the possibility of highlighting the natural levels that need to be protected and/or integrated, based on the 
implementation of an ecological network through the territory and the settlements.

From the characterisation of the territorial macro frameworks, it was possible to gradually identify specific aspects of the urban sector, following a criteria of gradual approaching to the building system, not only to meet the need of a generic "graduality" in approaching its problems, but, as previously said, because there is the strong belief that: "[...] each molecule of the anthropic universe is what it is in view of its relation with the others, which together constitute a structure. The result is that this complex framework of relations cannot be modified with arbitrary replacements, subtractions or additions, without damaging the urban or territorial framework of which each work is part" [4].

The words of Gaetano Miarelli Mariani in truth take back not only to the scalar logic that must be applied to the system both during the collection of the data, and during their analysis, but most of all to the provisional stage of the restoration project, which must be intended as the exploration of all the possible rational modifications of the physical-space orders of the manufacture, the aspect of which is linked to the present dynamic balance, and to its future prefiguration.

Remaining, for the moment, within the framework of the re-composition of the methodological process explored in the research, these words confirm that the quality of the urban settlement is affected by the rationality of the territory, and that in the case specific dimensional leap, the selected parameters for the description of both the natural system and the anthropic system at aggregate level (intended as an "intermediate condition" between the dimension of the territory and that of the building) must be the same, even if a separate in depth analysis is required. The density of the construction is for example one of the most basic criteria for the bioclimatic qualification of the local energetic structure. This can be described in its relation between the shape of the system and the sizing of the aggregate, between the quantity of the full sections and the empty ones in streets and yards, between the width of the paths and the height of the buildings, between the opening of the facades in the street plan, and the perception of the sky along the urban itineraries. Through the sensitivity of this, it is possible to prefigure the visual interferences that new technologies may generate in the existent, once they are introduced in the flow of the history of the settlement.

It is only with a further scale passage that it is possible to tackle the study of the building in the current consistency of its dimensional, historic, construction, language, typology, system, and utilisation components. These describe the material consistency, its development in the depth of the lot and the number of floors. From them emerges the permeability of the shape to the environmental system, in the presence or absence of arcades, open galleries, atriums, courtyards, and areas of pertinence. Historical information retraces the evolution of the manufacture in the main stages, transformations, and restorations to which it has been subjected during the times; it shows the discontinuities and provides data that intersect with the narration of the specificity of architecture. These take shape in the shell, which is investigated in terms of type of construction of the 
detected masonry work (materials, disposition, and quality of the binding agent), in the finishes and the adjectivation of the language system (present on the outside, as facade element, or on the inside), in the transparent elements, and in the orientations as integral and important wall interface system of the building.

Of these, which constitute the main traces on which the recomposition of the energy behaviours of the construction in relation to the outside environment is based, of substantial importance is the representation of the structures, the coverings, the insulation, the waterproofing, the types of glass, and any blockings. Lastly, the knowledge of the plant system inside the manufacture, as well as of its conservation status, the yield and the performance shortfalls, are of main importance when carrying out an energy assessment of the historic building. This is because through the collection and the analysis of these data it will be possible to easily identify waste, errors of positioning, and in more general terms the interferences with the construction system.

\section{The analysis of the modifiability of the as found status}

After ascertaining the need for observing the historical manufacture from a scalar perspective, so that from a large dimension it will be possible to gradually descend to the study of the own specific consistency of each individual construction, it is important to start interrogating oneself more directly on the sustainable perspectives of the architectural restoration, reconsidering it from an ecological point of view.

\subsection{Restoration and sustainability}

Restoration is a modern concept, mainly directed toward conservation, and aimed at ensuring that the fruits of human work are "taken into the future". It can be clearly explained in the project activity, and as it refers to already designed, built and sometimes restored architectural works, it recognises in its initial movement not a creativity or pure fantasy action, but rather a humble and cognitive approach based on the history of the manufacture and the context the same is part of.

The conservation of the material consistency of the manufacture, which can be obtained through the reduction of all deterioration factors present, is nevertheless insufficient in ensuring the persistence of the same across the times for future generations. The transmission of the heritage is in fact not automatic; it is necessary to take care of things, not just observing them with the eyes of the body, but looking at them with the eyes of the mind, and consider how they can be "used". Heidegger specifies that an object does not exist alone, separate from its use, because: "[...] its objectivity may not be perceived sensibly, but only in the way we understand it within the world of its possible use" [5]. It is nothing more than a full declaration in favour of the "rights of the manufacture" and its dutiful use. It is an anticipation of the principles included in the European Paper drawn in Amsterdam in 1975, and then reconfirmed in 1985 in Granada, in the postulate of the so-called "integrated conservation" of the architectural heritage. 
The close connection between the monument and its utilisation is therefore a guarantee for conservation and an intrinsic condition of the architecture, for which "pure contemplation" alone cannot be considered. In fact, it comes about as the formation within the environment of physical spaces intended for mankind. It is developed to meet a specific need, a particular function, a taste of the customer, and the artistic desire of the designer. In the definition given by William Morris, architecture is "the group of changes and alterations made on the surface of the earth following human needs" [6].

The qualifying intention that concerns each aspect of the social life of mankind is embodied, for the English expert, in the same idea of architecture, which includes all the applied arts and the range of acts that are at the heart of the organisation of a community. For this reason, each individual must feel that they are an active part in the preservation of the landscape, both natural and artificial, without entrusting to an "elite of trained men" the discovery, the shaping, and the preservation of the environment of which they are part. When interpreted in this way, art is detached from any style definition and aesthetic, or individualistic rule, and recognises in social value an extraordinarily modern point of reference. Sustainability can be many things at the same time. It is at the same time an idea, a life style, a way of producing and building, but also a simple "a la page" word that makes for stylish talks. One could say that sustainability in general is what diversifies a life condition or process that may be kept stable across the times. The Burndtland Report of 1987, compiled following approximately two years of work by the United Nations World Commission on Environment and Development, with reference to the apparent conflict between preservation of the environment and development of the civil society, has implemented this term as an "equilibrium in meeting current needs without compromising the possibility for future generations to satisfy their own". This concept is applied in many other areas, like environment and ecology, and now is gradually expanding to other fields of human activity. The various interpretations that can be found, as well as any newly formulated, about sustainability are connected with the many sides of the term, which may be defined both in a perspective of dialogue among the values, and as practical operating system of methodological, theoretical, and therefore political choices.

The consideration therefore lies in the relationship between man and the surrounding environment: whether the first is, or is not legitimised in intervening by manipulating and exploiting it, or if the environment is relevant in moral and ethical terms, so much so that human freedom in intervention strategies should be limited. Due to the social value recognised in the architectural work that is its object, design cannot be reduced to simple technical effectiveness, but indeed implies value choices, and is required to interpolate technological knowledge with an ethical respect for the environment.

In the discipline of restoration, the concept of sustainability may be defined in terms of interdependence of the conservation, protection, and function actions, of the existent, both in itself and in relation to the environment it is part of. So that, also as far as restoration is concerned, design choices are moved by an objective responsibility towards historic-aesthetic preservation of the manufacture, by an 
anthropological responsibility for the promotion of the relational social identification among man, manufacture, and environment, and lastly by an ecological responsibility for balance among the elements playing a part in the relational interdependence: historic manufacture, man, environment. The theories in the restoration field recognise in the centrality of the individual the genesis of the conservation process of an artefact, but do not exclude the complexity of the relationship of the same with the society, which gives the possibility of identifying heterogeneous values that make it possible to include the object in its surroundings. These thoughts do not imply a drift of objective criteria, always required during a scientific approach to matter, in an arbitrary subjectivism. They constitute, on the other hand, the recognition of the decisive importance of the recipient (who observes using the senses), and the awareness by the same (who becomes conscious through spirit) in the definition of the values of a historic building. Each monument much be respected not only for its historic-artistic values, whether they are low or high in importance, but also for its subjective value, we could say psychological, and the one that Alois Riegl defines "of antiquity", for the observing individual. The observer always has a decisive role: this happens in the construction of both the Riegl and the Brand analysis. The apperceptive action cannot in fact be considered an addition to the work, but remains a constitutive part of fundamental importance, as it allows the hermeneutic definition of the values intended as historic events, through which it is possible to create a connection among history, conservation, aesthetic, anthropology, and socio-politics. The productive role of the recipient therefore has a psychological importance, not in an abstract sense, but in an ethical one. The object-subject unit, which is at the basis of the interpretation of the work as mean of communication, is essential in the definition of the conservation frameworks, which does not deal with objects as such, extrapolated from the social-cultural context, but relates to those conditions for which a work becomes a testimony. This "sustainable" restoration strategy could therefore stand out because of the reciprocal interferences or interdependencies among the values recognised to the various components that qualify the architecture interpreted in the "Morris" sense, ensuring that the actions for the "transmission into the future" of an individual monument do not only have an intrinsic value, but also a global one, obtained from balancing together all the objectives pursued.

Similarly to what stated in the beginning, on the need for interpreting the historic manufacture following a scalar perspective, due to the fact that each work is strictly connected with its territory, also the preservation actions cannot only be directed towards the protection of an individual manufacture to the detriment of the surrounding environment, but on the contrary need to be assessed taking into account an overall evaluation of the needs and the responses that can be obtained from a certain framework in which a number of people leave and recognise themselves. The activities for the preservation of a natural habitat have different properties when compared to those for the conservation of the landscape, a historic centre, or a building, which are the result of the substance they are intended for, and for this reason may sometimes show contrasting or mutual exclusion elements. The commitment to comply, protect and preserve the 
current status of a manufacture, of a collective or personal heritage, is also associated with a conscientious activity for the maximization of the permanence of signs, the historic stratifications, and the aesthetic values recognised in the same. However, as substantial as it may be, this cannot imply the exclusion of the responsibilities that people have towards the territory they live in and in which they identify themselves through processes of perception of its natural and anthropic components; processes through which the environment becomes in itself a monument in a virtual rather than real dimension, nevertheless of no less historic value. According to Amartya Sen economy, in economy individual utility does not represent by itself the wellbeing of the person, which on the other hand is expressed through a series of other important aspects, like freedom, health, decorous work, pacific life of a community; in the same way, when considering a sustainable approach also restoration cannot be separated by the relational assessment of anthropological and environmental project choices [7].

The responsibility of the restoration action must tend towards compensation. This translates in the assessment of all the possible actions made available to mankind by historic and technological knowledge, for the actual permanence of a manufacture and the environment the same is part of. In other words, compensation could mean the possibility of assessing the existence of several possible combinations among reference factors, both in a synchronous sense (expanding the individual responsibilities towards the collective ones), and in a diachronic sense (by extending the correct preservation of the relation between man, artefacts, and environment to the future generations).

\subsection{Compatibility and mutation}

All this obviously does not express the total and undistinguished opening of historical cities to the technology and style works of architects. It is on the other hand a need for assessing the adaptation capabilities of innovations in becoming part of entities with a high degree of character. It means avoiding evasive and abusive interventions which, on the other hand, are on a technical, architectural and system point of view "compatible" with the existent.

Compatibility is a concept that in restoration has found answers mainly in the chemistry and physical fields, where it is the characters of the new matter introduced in the building system that are evaluated in relation to the pre-existing conditions. The materials, the procedures, the processes and the technologies that are essential for protecting works inherited from the past from decay must be evaluated in a way that does not entail the replacement, but rather the extension of the life of existing supports, without changing their material and visual consistency. Nevertheless, this is not sufficient for the rationalisation of the compatibility concept, which must necessarily be made clear for the safeguard and guarantee of the internal consistency of the possible choices. The identification of indicators capable of expressing at the same time the rational compensation and the material compatibility of restoration activities may prove to be a solution.

At this point, it becomes unavoidable to investigate the changes and permanencies that qualify the actuality of the framework spread throughout the 
historic city, and the possibility of the same to accept new and further modifications. Mutation is an intrinsic characteristic of the environment that has a strong capacity of adapting to the continuous variations required by human society across the times, during the various cycles of cultural development that set it apart. This is also a demonstration of the historic processuality of the urban structure, generated by a sequence of subsequent actions, each containing the previous act, which conditions and affects any formal and structural development of the social space. "The city is in fact [writes Paul Philippot] a living body, and therefore, by definition, in continuous metamorphosis" [8]. The idea of the city that arises from these words takes back to an "organic" image of the urban reality. A vision that finds its completion in the naturalistic spectacle given by the urban conglomeration consisting of architecture, streets, dusts, plants and noises, and which, as living being, grows, expands, and updates itself. Not unlikely, in comparing the environment to a book being continually written, an uninterrupted evolution process, which does not contain finished series of events, but open connections and sequences, subjected to continuous extensions, Kevin Lynch says: “...reading a place means understanding what happens, what happened, and what may happen" [9].

In the ubiquity of the present, the urban landscape is therefore subjected to constant changes, through alterations and extensions, each of them corresponding to a vital space, which is always the same, but also always different. This approach makes it possible to establish a compatibility between the stability of a place and the modification dynamics; in this way, for the urban scale, as well as the architectural one, the introduction of new elements may not be pushed back beforehand, in the ranks of superimposition, violation, devastation, safeguarded by the protection of the consolidated building framework. On the other side, by fully showing itself as a constitutional characteristic of the settlement framework, whilst conscious of all the surrounding, the change: territory, city, buildings, represents an important and irreplaceable resource, appears to recognise in continuous conservation and innovation the only possible design solution.

The characters of the relationship between permanence and innovation, although with some conceptual variations, appear rather aligned in the restoration discipline. However, in the field of the applicability of sustainable energy technologies to buildings in historic contexts, they do not yet receive appropriate methodological answers. On this respect, a system has been recognised, in the possibility of objectifying the innovative choices relating to the manufacture, expressed in the quality of "further modifications" required to the pre-existent by the recent needs shown by the society, for expressing the variations in the current layout in terms of interdependence of the restoration actions. The assessment parameters introduced in the system obviously respect the complexity of the relations between the parts making up the body, from the territory scale to the building one, and concern the identification, or the extension of the alterations already present in the macro element, considered in the specific interface relation with the environment. 


\section{ID Code}

Container progressive

Object progressive

\section{DENOMINATION}

\section{MODIFIABILITY OF THE SYSTEM IN RELATION TO THE REQUIRED ENERGY PERFORMANCES}

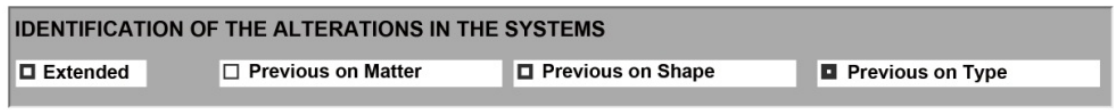

\begin{tabular}{|c|c|c|}
\hline \multicolumn{3}{|l|}{ DETECTABLE LEVEL OF ALTERATION } \\
\hline $0 \square \square \square \square \square$ Absence of previous alterations & $1 \square \square \square \square \square$ small alteration & $2 \square \square \square \square \square$ Medium alteration \\
\hline $3 \square \square \square \square \square$ Large alteration & $4 \square \square \square \square$ very large alteration & $5 \square \square \square \square \square$ Total \\
\hline
\end{tabular}

\begin{tabular}{|c|c|c|c|c|c|c|c|c|c|c|c|}
\hline 1 & MODIFIABILITY OF COVERS & & & & & & & & & DYES & 口NO \\
\hline & Modifiability indicators & Previou & & Lev & & & & & Extensior & & \\
\hline 年 & DDilapidation of the supporting structure & 口ם & 口 & 口 & 口 & 口 & 口 & 口 & $\square>2 / 3$ & 口 1/3-2/3 & $\square<1 / 3$ \\
\hline 흘 & 口 Condensations and infiltrations & 口ם & 口 & 口 & 口 & 口 & 口 & 口 & $\square>2 / 3$ & $\square 1 / 3-2 / 3$ & $\square<1 / 3$ \\
\hline 뜬 & 口Deterioration of the cover layer & 口ם & 口 & 口 & 口 & 口 & 口 & 口 & $\square>2 / 3$ & ㅁ1/3-2/3 & $\square<1 / 3$ \\
\hline $\mid$ & 口Other & $\square \square$ & - & 口 & 口 & 口 & 口 & 口 & $\square>2 / 3$ & ㅁ1/3-2/3 & $\square<1 / 3$ \\
\hline & 口 Lack of perception of the water table & 口ם & 口 & 口 & 口 & 口 & 口 & 口 & $\square>2 / 3$ & 口 1/3-2/3 & $\square<1 / 3$ \\
\hline & 口 Other & $\square$ & D & 口 & 口 & 口 & 口 & 口 & $\square>2 / 3$ & 口 1/3-2/3 & $\square<1 / 3$ \\
\hline
\end{tabular}

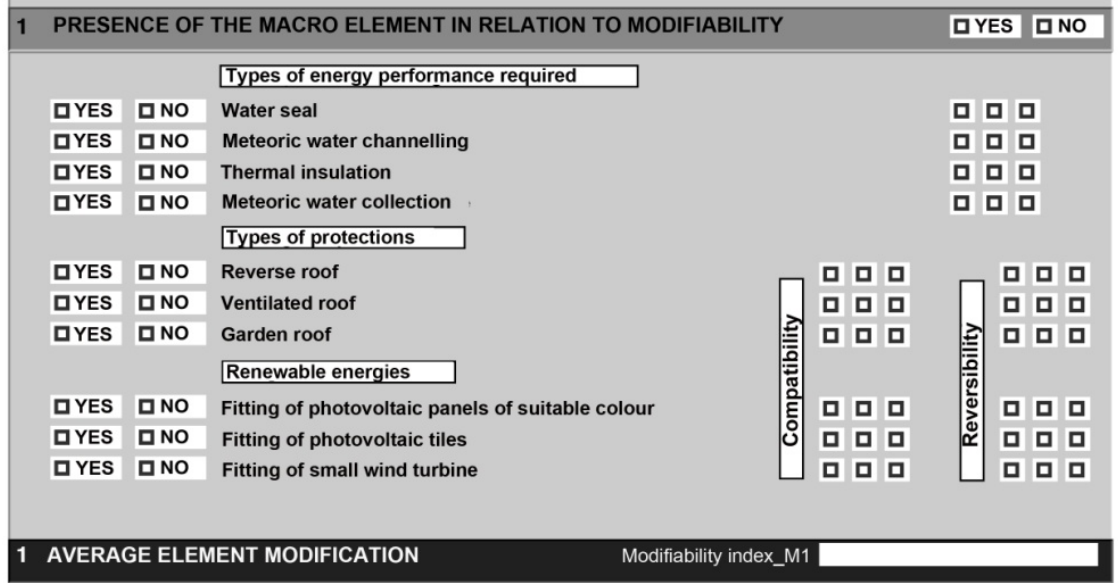

Figure 1: General diagram relating to the articulation of the modifiability parameters of the elements of the manufacture, analysed in relation to performance efficiency, conservation status, and compatibility of the innovation.

Modifiability indicators, expressed in terms of compensation and compatibility of restoration actions have been researched mainly in the condition of the current status of components, due to the fact that they constitute a basic 
factor that must be carried out and must be subjected to evaluation. This procedure does not only entail a search for particular values or typical qualities of the historic heritage, but rather aims at characterising what in its matter has already been transformed, what in the physical consistency of a building has already been changed by previous restorations, by more or less large replacements of materials, by alterations made to its morphological consistency. It's a matter of understanding how many and which changes have already been made to the linguistic system, to the structural and the distributive one, and how much both the building itself and its urban structure are still able to withstand further transformations. Therefore, everything rotates around the dialectic between continuity and mutations, innovation and traditions, and therefore on the temporal value of the historic sequence and on the type of conservational design activities that can be assumed. All forms of alteration of the manufacture and the structure have been little by little defined in terms of intensity, extension and type, as well as compared with the required energy performance of the element, and the level of innovation that can be introduced in the system, also defined in terms of durability, reversibility, and compatibility.

The methodological process that we have decided to synthetically show is meant as a possible tool for reading the historic manufacture, and a rational system for directing permanence and minimizing innovation. All this, with the understanding that an attempt has been made, to objectify what is unavoidably subjected to judgement, and therefore in itself transient.

\section{References}

[1] Christian Norberg-Schulz, Genius Loci: paesaggio, ambiente, architettura, Electa, Milano 2000.

[2] Giacomo Devoto, Giancarlo Olii, Dizionario della lingua italiana, entry Climate, Milan 2010.

[3] Gaetano Miarelli Mariani emphasizes in fact that it is not correct "...to separate the analysis from the project, unless for purely instrumental purposes, as we are talking of two inseparable stages of a unique process, between which it is not possible and there must not exist a rigorous and mechanic temporal succession." Gaetano Miarelli Mariani, Restauro e territorio. Appunti su un rapporto difficile e controverso, in "Palladio" XXV 1978, pp. 83-100.

[4] Gaetano Miarelli Mariani, Restauro e territorio. Appunti su un rapporto difficile e controverso, in "Palladio" XXV 1978, pp. 83-100.

[5] Heidegger, M., Costruire Abitare pensare (Chapter 1), in Id. Essays and Speeches, by G. Vattimo, Mursia, Milan 1991, p. 375.

[6] William Morris, Architettura e socialismo, Laterza, Bari 1963, pp. 3-4.

[7] Amartya Sen, Etica ed economia, Laterza, Bari 2006.

[8] Paul Philippot, I colori di Roma, in Id., Saggi sul restauro e dintorni. Antologia, by P. Fancelli, Bonsignori, Rome 1998, p. 73.

[9] Kevin Lynch, L'immagine della città, Marsilio, Venice 2006. 